DOI https://doi.org/10.17308/vsu.proc.law.2021.2/3400

\title{
ПОКАЗАНИЯ В УГОЛОВНОМ ПРОЦЕССЕ: СОДЕРЖАНИЕ ИЛИ ФОРМА?
}

\author{
В. А. Лазарева \\ Саларский наииональный исследовательский университет \\ илени академика С. П. Королева \\ Поступила в редакцию 15 февраля 2021 г.
}

\begin{abstract}
Аннотация: расслатриваются актуальные проблель допустилости показаний в качестве доказательств по уголовнолу делу. Обосновывается тезис о разделении в систеле доказательств показаний свидетелей, потерпевших, обвиняельх и подозреваелых и протоколов допроса этих участников уголовного процесса по основанию наличия/отсутствия непосредственности восприятия инфорлации субъектол, принимающил процессуальное решение, оспаривается возложность использования протоколов допроса в качестве доказательств в состязательнол судопроизводстве.

Ключевые слова: показания свидетеля (потерпевшего, обвиняелого, подозреваелого), видь доказательств, допрос, непосредственность судебного разбирательства.
\end{abstract}

\begin{abstract}
: the article deals with the actual problems of the admissibility of testimony as evidence in a criminal case. The article argues that the division in the evidence of witnesses, victims, defendants and suspects, and protocols of the interrogation of the participants in criminal proceedings on the basis of the presence/absence of perception of the information by the entity that receives a procedural decision, disputed the possibility of the use of protocols of interrogation as evidence in adversarial proceedings.
\end{abstract}

Key words: testimony of a witness (victim, accused, suspect), types of evidence, interrogation, immediacy of the trial.

19 декабря 2020 г. в Северо-Западном филиале Российского государственного университета правосудия (г. Санкт-Петербург) состоялся круглый стол, на котором в достаточно узком оппонентском круге обсуждался широкий круг вопросов, связанных с допустимостью использования в качестве доказательств показаний физических лиц, допрашиваемых в том или ином процессуальном статусе при производстве по уголовному делу. Сразу скажем, что мероприятие, оказалось не только полезным, но и интересным, затронувшим множество вопросов, неоднозначно решаемых в практике и дискуссионных в теории. Состоявшийся обмен мнениями, как обычно, побуждает к уточнению или пересмотру собственной позиции, привлекает внимание к тем аспектам, которые казались ясными или малозначимыми.

Интерес к показаниям как виду доказательств не случаен. Этот вид доказательств наиболее востребован практикой, присутствует во множестве в каждом уголовном деле, нередко выполняет роль прямого, а зна-

(C) Лазарева В. А., 2021 


\section{Вестник ВГУ. Серия: Право}

чит, весьма значимого доказательства. В числе обсуждаемых значительный удельный вес приходится на проблемы, так или иначе связанные с использованием в качестве судебных доказательств показаний, полученных в ходе предварительного расследования. Выступающие указывали на распространенность таких явлений, как применение недобросовестных методов в процессе получения показаний подозреваемого, обвиняемого, неявку свидетелей и потерпевших в судебное заседание, необъективность (или сложность объективной) оценки показаний. Звучали также вопросы, связанные с не всегда ясным статусом доказательств и участников процесса, значением показаний эксперта и специалиста, психологией допроса и др. Среди обсуждаемых проблем есть как старые, давно известные, но не решеные, так и возникшие сравнительно недавно, в связи с не всегда удачными изменениями законодательства. Иногда и старые проблемы благодаря законодателю обретают новую остроту, как это произошло с введением в число участников уголовного процесса лица, в отношении которого уголовное дело выделено в отдельное производство в связи с заключением с ним досудебного соглашения о сотрудничестве, статус которого оставляет сомнения ${ }^{1}$, или с легализованной возможностью использования в качестве доказательств объяснений, полученных в ходе опроса, проведенного как официальными лицами - следователем, дознавателем, так и адвокатом-защитником.

По мере выступлений участников круглого стола приходило осознание: к решению проблем допустимости использования в качестве доказательств сведений, сообщаемых участниками уголовного процесса, имеющими тот или иной процессуальный статус, нельзя подходить без учета принципа состязательности, из которого логически вытекает возможность решения указанных выше проблем путем разведения показаний

$\sim$ и протоколов допроса как двух взаимосвязанных, но не равнозначных 인 видов доказательств.

Приведем аргументы. Состязательность уголовного судопроизводства теснейшим образом связана с независимостью суда, с его способностью приходить к самостоятельным выводам и решениям. Роль независимого от сторон арбитра суд может реализовать только будучи способным воспринимать доказательственную информацию в ее естественном, первоначальном, виде. Казалось бы, на это и указывает ст. 240 Уголовно-процессуального кодекса РФ (далее - УПК РФ), содержащая требование о непосредственном исследовании судом всех доказательств, однако при вдумчивом анализе этого важнейшего общего условия судебного разбирательства возможность его исполнения достаточно легко поставить под сомнение.

Возникает вопрос - почему, который можно отнести к разряду риторических. Согласно ст. 240 УПК РФ объектом непосредственного судебного исследования являются доказательства, которые предстают перед судом в единстве своего содержания и формы, фрактически и как правило - в

${ }^{1}$ См.: Лазарева В. А. Лицо, в отношении которого... // Мировой судья. 2019. № 2. C. 15-19. 
виде документов, составляющих львиную долю всех материалов уголовного дела, не считая вещественных доказательства, хотя и они уже «отдали» информацию документам в ходе производства следственных действий и экспертных исследований. Конечно, суд может, а иногда и должен осмотреть предмет или документ, когда свойства, имеющие значение для установления тех или иных обстоятельств, не отделимы от их носителя или когда доказательственная информация заключается в признаках самого объекта, но в большинстве случаев ценность вещественного доказательства состоит в отделимой от него информащии, которая сохраняется и интерпретируется в письменных материалах дела - в протоколе осмотра, заключении эксперта. Таким образом, объем непосредственного - без посредника - исследования доказательств судом ограничен возможностью: а) осмотра вещественных доказательств и б) выслушивания устных показаний свидетелей, потерпевших и подсудимых, а с определенной долей условности также экспертов и специалистов. Отсюда исключительная ценность судебного допроса как способа получения судом информации непосредственно от ее носителя.

Таким образом, мы подходим к сути вопроса о соотношении показаний фризического лица и протокола его допроса.

Обычно протокол допроса рассматривается как естественная форма сохранения, средство фриксации показаний ${ }^{2}$, которые в этом случае являются лишь содержанием протокола. В наиболее четкой форме эту мысль выразил В. А. Семенцов. По его мнению, если «в протоколе следственного действия фиксируются сведения, полученные от других лиц (протокол допроса подозреваемого, обвиняемого, потерпевшего, свидетеля, эксперта, специалиста), то он относится к доказательствам соответствующего вида (показания подозреваемого, обвиняемого и др.)». Между тем показания названы в ч. 2 ст. 74 УПК РФ в общем перечне видов доказательств наряду с протоколами следственных действий, к числу которых, безусловно, относятся протоколы допроса и очной ставки, ибо допрос и очная ставка это следственные действия. Один вид доказательств (показания) не может рассматриваться в качестве содержания другого вида доказательств (протокола). Содержанием показаний являются сообшаелые лицом сведения, в то время как в протоколе зафиксированы сообщенные сведения. Между сообщаемыми и сообщенными сведениями огромная разница. Не случайно практика с большим недоверием относится к показаниям с чужих слов, а здесь мы фрактически имеем письменную форму изложения чужого устного сообщения.

Показания, как известно, есть доказательство личное, исходящее от физического лица, прошедшее через его сознание ${ }^{4}$, продукт его психи-

${ }^{2}$ См.: Новиков С. А. Показания обвиняемого в современном уголовном процессе России / науч. ред. А. И. Александров. СПб., 2004. С. 143.

${ }^{3}$ Селениов В. А. Следственные действия в досудебном производстве. М., 2017. C. 177.

${ }^{4}$ См.: Григорьев В. Н., Победкин А. В., Яшин В. Н. Уголовный процесс : учебник. М., 2005. С. 177. 


\section{Вестник ВГУ. Серия: Право}

ческой деятельности, его способности отражать в своем сознании окружающий мир и передавать результаты отражения другим лицам. Показания - речь, поток словесно оформленной устной информации, это не столько результат, сколько процесс - процесс передачи информации посредством осмысленных высказываний. Последовательность высказываний, передающих смысловую информацию, есть текст, занимающий в современной культуре значительное место, рассматриваемый в ней не как способ отражения реальности, а как способ ее создания ${ }^{5}$ Смысловое описание реально лишь в момент, когда оно существует ${ }^{6}$. Таким образом, любые показания краткосрочны, существуют лишь в момент речевой передачи информации. Говоря словами А. Р. Ратинова, показания - это исходящая от лица информация ${ }^{7}$, которая не существует вне своего речевого носителя ${ }^{8}$.

Протокол допроса - тоже личное доказательство, которое благодаря той же способности другого лица (в данном случае следователя или дознавателя) фрормируется в его сознании, а потом на бумаге. Однако протокол допроса - это уже другой текст, т. е. другая реальность. Можно утверждать, что протокол допроса есть продукт психической деятельности двух лиц, каждая (деятельность) из которых, протекая в соответствии с общими закономерностями, обладает неповторимым индивидуальным своеобразием. Мы не рассматриваем здесь протокол очной ставки, поскольку он является особенной разновидностью протокола допроса, состоящего из двух самостоятельных протоколов - во всяком случае в рассматриваемом ракурсе - одновременно осуществляемых допросов.

Нужно ли говорить, что протокол допроса как следственного действия отражает отнюдь не обстоятельства преступления, воспринятые, например, свидетелем или потерпевшим, а результат восприятия (отражения),

в данном случае сообщения, следователем. В процессе допроса и прото-

이 колирования происходит неоднократное преобразование информации по форме (словесное сообщение допрашиваемого преобразуется в сознании следователя в образы и обратно в слова, ложащиеся на бумагу), следовательно, неизбежно происходит искажение и утрата информации, понижение уровня ее адекватности. В работах по судебной (юридической)

206 психологии этот механизм достаточно описан. Протокол допроса в свете этих закономерностей если и может быть рассмотрен как доказательство, то лишь как производное, как текст, написанный с чужих слов. Криминалистические рекомендации и даже законодательные предписания (записывать ответы, по возможности, дословно, записывать все вопросы и в той последовательности, в которой они имели место в ходе допроса, включая те, на которые не был дан ответ, запрет наводящих вопросов и т. д.)

${ }^{5}$ См.: Руднев В. П. Словарь культуры ХХ века. М., 1997. С. 170, 323-333 и др.

${ }^{6}$ См.: Цветков Э. А. Имагинатор. М., 2005. С. 11-12 и др.

${ }^{7}$ См.: Ратинов А. Р. Судебная психология для следователей. М., 2001. С. 209.

${ }^{8}$ См.: Леднев E. A. Показания свидетеля как уголовно-процессуальное доказательство : дис. ... канд. юрид. наук. Н. Новгород, 2006. С. 23. 
нежизнеспособны, и их очевидное несоблюдение на практике вызывает массу обсуждаемых в теории вопросов. При этом следователь, составивший протокол допроса, в отличие от свидетеля, дающего показания с чужих слов, не может быть допрошен в суде об обстоятельствах получения им информации, во-первых, и не может рассматриваться как объективный источник информации с чужих слов, во-вторых, поскольку, несмотря на все оговорки об обязанности вести расследование объективно и всесторонне, следователь отнесен к стороне обвинения, от которой и должен быть независимым беспристрастный суд.

Показания и протоколы (допроса, очной ставки), таким образом, есть два разных вида доказательств, каждый из которых имеет собственные содержание и форму. Показания в этом смысле можно рассматривать как специфическое тождество его содержания и формы, где форма есть человеческая речь, словесный информационный код9.

Не тождественность показаний и протоколов допроса обязывает суд к непосредственному заслушиванию устных сообщений тех свидетелей, потерпевших и подсудимых, допрос которых анонсирован сторонами и который является способом представления ими доказательств. Оглашение протокола допроса не является способом непосредственного восприятия судом информации. Оглашая протокол, суд воспринимает лишь тот процессуальный результат, который был достигнут производившим допрос следователем или дознавателем. Индивидуальность восприятия в сочетании с многомерностью и многослойностью реальности обусловливает его зависимость от множества не только объективных, но и субъективных факторов и не допускает возможности замены восприятия одного субъекта восприятием другого. Как отмечал С. А. Шейфер, человеческое восприятие есть не механическое отражение мира, а процесс его интерпретации, осознания, которое может быть и нередко бывает ошибочным ${ }^{10}$.

Понимание показаний исключительно как непосредственно воспринимаемых судом устных сообщений фризических лиц приобрело особое значение в момент закрепления состязательности в качестве принципа уголовного судопроизводства. Логический ряд: состязательность процесса - независимость суда - свобода внутреннего убеждения своим естественным продолжением имеет непосредственность восприятия судом информации, формирующей его свободное внутреннее убеждение, независимое от предварительных выводов органов предварительного расследования и предварительной же оценки ими тех доказательств, на которых основано предъявленное лицу обвинение. Именно на это указывает ст. 240 УПК РФ, хотя достаточными гарантиями требование непосредственности исследования доказательств сегодня не обеспечено, о чем свидетельствуют слишком широкие возможности оглашения следственных

${ }^{9}$ См.: Белкин Р. С. Ленинская теория отражения и методологические проблемы советской криминалистики. М., 1970. С. 11.

${ }^{10}$ См.: Шейøер С. А. Следственные действия. Система и процессуальная форма. М., 2001. С. 13-14. 


\section{Вестник ВГУ. Серия: Право}

протоколов допроса. Называя их при этом показаниями, данными при производстве предварительного расследования (ч. 2 ст. 240, ст. 267, 281 УПК РФ), закон навязывает вывод о тождественности показаний и протоколов как доказательств, на основе которых фрормируется внутреннее убеждение суда. Как заметил в ходе своего выступления А. С. Александров, состязательности и справедливости уголовного процесса у нас никто не отрицает, но гарантом их странным и нелогичным образом признается следователь.

Стоит отметить, что наш уголовный процесс в первоначальной редакции УПК РФ был гораздо ближе к состязательному, чем сегодня. Достаточно указать, что ст. 281 оглашение протоколов допроса свидетеля и потерпевшего допускалось исключительно с согласия обеих сторон, но уже 4 июля 2003 г., т. е. спустя всего один год после вступления нового УПК в действие, право сторон влиять на это решение суда было сведено к минимуму. Вопрос о том, в чью пользу были приняты эти изменения, можно считать риторическим. Общая тенденция очевидна - неявка в суд свидетелей и потерпевших препятствует осуществлению обвинительной деятельности, однако избранный способ решения этой проблемы не является, что очевидно, удачным. Между тем состязательная логика нашему законодателю известна. Так, суд не вправе отказать в допросе свидетеля или специалиста, явившегося по инициативе сторон (ч. 4 ст. 271 УПК РФ), из чего следует, что он вправе отказать в удовлетворении ходатайства о допросе не явившегося по инициативе стороны свидетеля. Рассуждая далее, приходим к простому и понятному выводу - любая сторона, желающая допросить важного для подтверждения ее позиции свидетеля, обязана обеспечить его явку в судебное заседание. Сторона, не выполнившая это условие, не вправе рассчитывать на помощь суда, однако в отношении стороны обвинения, которая по понятным причинам имеет бо́льшие, чем вторая сторона, возможности для обеспечения явки свидетелей, законодатель делает очередное - неоправданное - послабление, усугубляющее ситуацию.

В 2016 г. в ст. 281 УПК РФ внесено дополнение, согласно которому оглашение протокола допроса свидетеля и потерпевшего без согласия сторон возможно и в случае, когда в результате принятых мер не установлено его место нахождения для вызова в суд, при условии, что стороне защиты в предыдущих стадиях процесса была предоставлена возможность оспорить эти доказательства предусмотренными законом способами. Даже отбросив все другие, в том числе приведенные выше, аргументы, позволительно спросить: разве реализованная в ходе расследования возможность оспорить показания свидетеля исключает или уменьшает для суда ценность непосредственного восприятия его устного сообщения? Став на этот путь, пожалуй, можно договориться и до полного отказа от судебного допроса как способа познания обстоятельств преступления, а далее и от судебного следствия как такового. Впрочем, такой способ принятия судебного решения нашему законодательству, кажется, известен (ст. 226.9, 315, 317.7 УПК РФ). Условием его применения является отсут- 
ствие спора, взаимный и добровольный отказ от состязания, достигнутый сторонами по всем существенным вопросам компромисс.

При наличии спора судебный процесс должен следовать принципу состязательности, что, впрочем, не исключает возможности достижения согласия по вопросу о наличии/отсутствии необходимости (перекрестного) допроса свидетелей и потерпевших сторонами судебного процесса.

Вопрос об оглашении протоколов допроса подозреваемых и обвиняемых в состязательной судебной процедуре в перспективе должен быть снят. Рассматривая показания подозреваемого, обвиняемого как доказательство, допуская оглашение протокола его допроса при отказе от дачи показаний или наличии противоречий между протоколом допроса и устными сообщениями в суде, мы обычно придаем им особое значение в случае признания вины и не придаем никакого значения при ее отрицании. Гарантии добровольности признания вины (и допустимости доказательства) в виде присутствия при следственном допросе защитника не эфрфективны. Однако оспорить достоверность этого признания практически невозможно, поскольку любые показания подсудимого о недобровольности досудебного признания вины признаются председательствующим недопустимыми, а сама попытка оспорить эту достоверность - незаконным воздействием на судей, включая присяжных заседателей. Исключив возможность использования в суде протокола допроса подозреваемого, обвиняемого, мы решаем и эту и другие проблемы, с ней связанные. Например, обвиняемый получит реальную возможность пользоваться правом отказаться от защитника, которого ему сегодня “навязывают» в целях закрепления признания, давать показания и отказываться от них без риска неблагоприятных последствий, если мы признаем свободу выбора им позиции. Впрочем, возможны и другие варианты более логичного, чем сегодня, правового регулирования, когда показания обвиняемого, не несущего уголовной ответственности за ложь, рассматриваются как допустимое и достоверное доказательство даже при отрицании вины в суде.

Обособление показаний от протоколов допроса может способствовать решению ряда других практически значимых вопросов, в том числе тех, которые активно обсуждались участниками упомянутого круглого стола. В частности, могут быть сняты с обсуждения вопросы, связанные с допустимостью использования любых документов, содержащих запись сообщений фризических лиц - объяснений, полученных до возбуждения уголовного дела, явки с повинной, а также результатов адвокатского опроса, проведенного в соответствии с п. 2 ч. 3 ст. 86 УПК РФ, иных документов, содержащих запись устных сообщений фризических лиц, в том числе при производстве следственных и иных процессуальных действий. Суды перестанут допрашивать в качестве свидетелей сотрудников полиции об информации, которую им якобы сообщил обвиняемый вне допроса и т. д. Для решения этих и других вопросов не обязательно переписывать Уголовно-процессуальный кодекс целиком, достаточно для начала просто исключить возможность оглашения в суде протоколов допросов без согласия обеих сторон. 


\section{Библиографический список}

Белкин Р. С. Ленинская теория отражения и методологические проблемы советской криминалистики. М. : Изд-во ВШ МВД СССР, 1970. 130 с.

Григорьев В. Н., Победкин А. В., Яшин В. Н. Уголовный процесс : учебник. М. : Эксмо, 2005. 827 с.

Лазарева В. А. Лицо, в отношении которого... // Мировой судья. 2019. № 2. C. 15-19.

Леднев E. A. Показания свидетеля как уголовно-процессуальное доказательство : дис. ... канд. юрид. наук. Н. Новгород, 2006. 240 с.

Новиков С. А. Показания обвиняемого в современном уголовном процессе России / науч. ред. А. И. Александров. СПб. : Изд. дом С.-Петербургского гос. ун-та, 2004. 240 с.

Ратинов А. Р. Судебная психология для следователей. М. : Юрлитинформ, 2001. $352 \mathrm{c}$.

Руднев В. П. Словарь культуры ХХ века. М. : Аграф, 1997. 381 с.

Семенцов В. А. Следственные действия в досудебном производстве. М. : Юрлитинформ, 2017. 256 с.

Цветков Э. А. Имагинатор. М. : Астрель : АСТ : Люкс, 2005. 301 с.

Шейфер С. А. Следственные действия. Система и процессуальная форма. М. : Юрлитинформ, 2001. 208 с.

\section{References}

Belkin R. S. Lenin's theory of reflection and methodological problems of Soviet criminalistics. M., 1970. 130 p.

Grigoriev V. N., Povetkin A. V., Yashin V. N. Criminal procedure: Textbook. M. : Eksmo, 2005. 827 p.

Lazareva V. A. The person in relation to whom // Justice of the Peace. 2019. No. 2. P. $15-19$.

Lednev E. A. Testimony of a witness as criminal procedural evidence. Diss ... Ph. D. N. Novgorod, 2006. 240 p.

Novikov S. A. The testimony of the accused in the modern criminal process of Russia. St. Petersburg : Publishing House of S.-Peterb. State university, 2004. $240 \mathrm{p}$.

Ratinov A. R. Forensic psychology for investigators. M. : Yurlitinform. 2001. $352 \mathrm{p}$.

210 Rudnev V. P. Dictionary of twentieth-century culture. M. : Agraf, 1997. 381 p.

Sementsov V. A. Investigations in pre-trial proceedings. M. : Yurlitinform, 2017. $256 \mathrm{p}$.

Tsvetkov E. A. Imaginator. M. : Astrel : AST : Lux, 2005. 301 p.

Schaefer S. A. Investigative actions. System and procedural form. M. : Yurlitinform, 2001. 208 p.

Салмарский национальньй исследовательский университет илени С. П. Королева

Лазарева В. А., доктор юридических наук, профбессор кафбедры уголовного проиесса и крилиналистики

E-mail:v.a.lazareva@mail.ru
Samara National Research University named after $S$. P. Korolev

Lazareva V. A., Doctor of Legal Sciences, Professor of the Criminal Process and Criminalistics Department

E-mail:v.a.lazareva@mail.ru 